\title{
Experimental tests on a new harvesting system for Burley tobacco
}

\section{Salvatore Faugno, ${ }^{1}$ Collins Okello, ${ }^{1,2}$ Roberta Infascelli, ${ }^{1}$ Francesca Audino, ${ }^{1}$ Luca Ardito, ${ }^{1}$ Stefania Pindozzi ${ }^{1}$}

\author{
${ }^{1}$ Dipartimento di Agraria, Università di Napoli Federico II, Italy; ${ }^{2}$ Department of Biosystems \\ Engineering, Gulu University, Uganda
}

\begin{abstract}
The globalization of the tobacco production has led to a drop in competitiveness of the Italian tobacco on the world market. Burley is the main variety of tobacco cropped in Campania region of Southern Italy. Its leaves have to be sewn, in the curing phase. Aim of this work is to show the results of the implementation of a new harvest machine prototype. Basically, the machine used for Bright tobacco, totally mechanical harvested, which doesn't need to be sewn because it requires an indirect-fire treatment into the curing furnaces. The machine was modified in order to mechanize harvesting of Burley tobacco, and tested on four cultivars of Burley tobacco under three different planting layouts. The Burley tobacco leaves can be harvested mechanically by pulling individual leaves off the stalk; leaves are then sorted and tied in bundles prior to sewing. A mechanical burley tobacco harvesting system was evaluated. This machine consists in realizing a leaves orientation system based on the different weight between the leaf blade and the stalk enhanced by an air flow. The measurements taken were
\end{abstract}

Correspondence: Stefania Pindozzi, DIA, Università degli Studi di Napoli Federico II, via Università 100, 80055 Portici (NA), Italy.

Tel. +39.081.2539128.

E-mail: stefania.pindozzi@unina.it

Key words: Burley tobacco, mechanical harvesting, harvest timing.

Contributions: the authors contributed equally.

Conflict of interests: the authors declare no potential conflict of interests.

Funding: the work was supported by Campania Region with Tab.It Project.

Acknowledgments: The research activities were made under the project "Technical innovations and organizational restructuring of the tobacco sector in Campania region, in compliance with quality productions (Tab.IT)", funded by the Rural Development Policy 2007-2013, Measure 124 of Campania Region aimed at identifying techniques of cultivation of burley tobacco with low energy input pursuing the complete mechanization of the crop cycle. The authors would like to thank Spapperi s.r.l. and prof. I. Sifola for their support.

(C) Copyright S. Faugno et al., 2013

Licensee PAGEPress, Italy

Journal of Agricultural Engineering 2013; XLIV(s2):e72

doi:10.4081/jae.2013.s2.e72

This article is distributed under the terms of the Creative Commons Attribution Noncommercial License (by-nc 3.0) which permits any noncommercial use, distribution, and reproduction in any medium, provided the original author(s) and source are credited. harvest timing, work capacity, and quality standards of the work carried out. The results, in terms of user time, range from $6.67 \mathrm{~h} / \mathrm{ha}$ to $7.80 \mathrm{~h} / \mathrm{ha}$ while in terms of operational efficiency are between $88 \%$ and $89 \%$. The average user capacity recorded for the four cultivars is equal to $0.14 \mathrm{ha} / \mathrm{h}$, a value far from the one recorded for the same harvesting machine used for Bright tobacco $(0.25 \mathrm{ha} / \mathrm{h})$. The harvest timing capacity, range from $0.51 \mathrm{t} / \mathrm{h}$ to $0.99 \mathrm{t} / \mathrm{h}$. The work productivity goes from $0.17 \mathrm{t}$ to $0.33 \mathrm{t}$ per hour of human unit respectively. The average number of detached leaves, depending on the cultivar, has been between 523 and 744 . Concerning the leaf orientation, a general percentage of $73 \%$ was achieved.

\section{Introduction}

Tobacco cultivation in Europe is not immune to the effects of markets globalization which has created a sudden loss of competitiveness of Italian products compared to those available on the world market. The Italian agricultural system is burdened with a high cost of labor, because the crops are not fully mechanized.

The imbalance between production costs and the tobacco price was attenuated until 2006 due to the direct subsidy under the Common Agricultural Policy (CAP) and the Tobacco Common Market Organization (CMO). Since 2003, after an important reform in the CAP, subsidies were "decoupled" from particular crops. This led to a tremendous reduction of lands under tobacco cultivation. In Italy, the total area of land under tobacco cultivation reduced by approximately $28 \%$. In the North of Italy, there was an increase in the average size of specialized tobacco farms, while the average size of the farms remained unchanged in Campania region (ISTAT, 2010). The decrease in production in Campania region was more than $43 \%$. This difference in production between Campania region and other Italian areas is attributable to discrepancy in the production cycle. The bright-leaf tobacco is the variety mainly grown in the North of Italy, for which it is possible to implement the mechanical harvesting. However, harvesting of the burley tobacco cultivar, which is cultivated in the South Italy, remains highly labor intensive.

Despite these difficulties the Italian tobacco industry occupies a prominent position in the international scene, with a production of 89 kt $\mathrm{y}^{1}$, represents $26 \%$ of the total European production (NOMISMA, 2011). The cultivation of tobacco contributes less than $1 \%$ on the gross marketable production of Italian agriculture, and is mainly concentrated in four Italian regions of Campania, Tuscany, Umbria and Veneto. The tobacco industry employs approximately 204,000 persons throughout the supply chain (Di Carlo, 2012).

The mechanical systems for burley tobacco harvesting has not been investigated adequately despite numerous efforts to develop mechanize the operation over the last 30 years (Casada et al. 1972; Yoder \& Henson, 1974; Duncan et al. 1996, 1999; Wells et al. 2011). One of the major limitations in the mechanical harvesting of burley tobacco is 
related to the disposition of the leaves, which are not orderly arranged during harvesting and must be reorganized and put in bundles before being stuck for air-curing.

The aim of this study is to evaluate a new harvester prototypes realized within the project "Technical Innovations and Organizational Restructuring of the Tobacco sector in Campania region, Respecting Quality Production" (Tab.IT). The project aimed at identifying techniques of cultivation of Burley tobacco with low energy input and implementing the complete mechanization of the crop cycle. The prototype consists of a leaves orientation system based on the difference in weight between the leaf blade and the petiole and enhanced by an air flow. The prototype was the result of collaboration between the Department of Agriculture of University of Naples Federico II and an agro-machinery manufacturing company, Spapperi Srl of San Secondo (PG). The prototype was a modification of the bright-leaf tobacco harvesting machine. The system was improved and results of field tests were reported in order to evaluate the functionality of the system, the quantity and quality of work. The tests were carried out on four cultivars of Burley tobacco and with three different planting densities, with variation only in the distance between plants in the row. The row spacing was kept constant to allow the passage of the harvesting machine.

\section{Materials and methods}

\section{Collection technique}

The prototype was designed based on the Bright-leaf tobacco harvesting system. The Bright-leaf tobacco is intended for kiln-drying; therefore, the leaves collected are discharged directly in the loading system of the drying oven. However, burley tobacco is air-cured and the leaves have to be bundled and sewed after harvesting. The bundles are then hanged on special supports in cold greenhouse and allowed to dry. In order to perform the sewing, the leaves have to be mostly intact and all arranged with the stalk from the same side. This diverse need of care is the main challenge mechanical harvesting burley tobacco. Currently this type of tobacco is collected by workers, who advance between the rows, manually detaching the leaves and forming bunches, already oriented to be allocated to the next phase of sewing. As reported by CRAA in 2006, the manual labor requirement, for conventional harvesting is approximately $74 \mathrm{w}$-h/ha, including the time required for retrieving filled sticks from fields and hanging in barns for curing.

\section{Experimental site}

The experimental tests were carried out on a plot of 1 ha, located in Vitulazio in the South of Italy. Harvesting operations were observed and documented during the 2012 burley season at the Società Agricola Alessia Srl. The harvesting trials were carried out with four cultivars of Burley tobacco i.e., CD, DD, BD and PM34, which is typically grown in the Caserta province, as the control. The first three cultivars reached a height of around $2.20 \mathrm{~m}$. All the cultivars were planted at spacing between plant in rows of $0.25 \mathrm{~m}, 0.30 \mathrm{~m}$ and $0.33 \mathrm{~m}$, while row length was kept constant at $0.90 \mathrm{~m}$.

\section{Description of machinery and harvesting mode}

The Spapperi prototype, a modification of the Bright tobacco harvesting machine, is able to obtain pre-orientation of leaves, forming bunches ready for sewing, which takes place in the field. The system for the orientation of leaves is based on the weight difference between the leaf lamina and petiole, and on the increased aerodynamic drag of leaves. To this end a tapered section downwards metallic channel, has been mounted on the machine.

A blower (Figure 1a), was positioned at the base of the hopper to create an ascending air current that ensure orientation of leaves. The leaves from the elevation system are conveyed up in a pneumatic hopper from where they fall on a conveyor belt (Figure 1b). During the descending phase they are positioned with down stem. At the exit of the hopper the leaves are intercepted by a conveyor belt which transfers them in a container (Figure 1c).

\section{Data collection}

The experimental tests were carried out to evaluate system productivity. The measurements taken were harvesting time, working time, and quality of work. Analysis of working times was conducted according to the CIOSTA (Commission Internationale de l'Organisation Scientifique du Travail in Agriculture) official methodology and to recommendations of Italian Association of Rural Engineering (AIGR) 3A R1. Working times were split into time elements of the functional process analyzed, and consisted of the gross working time, which included the accessories times and unproductive times (Magagnotti et al. 2013, Fedrizzi et al. 2012). All time elements and the related time-motion data were recorded with a chronograph. Measurements were made timing the various phases at the cycle level, where the harvesting of a full unit was considered as a complete cycle (Magagnotti et al. 2013).

The tests were carried out over the length of the $400 \mathrm{~m}$ rows of four

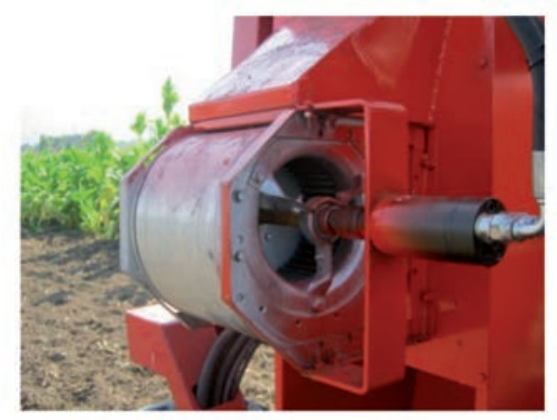

a)

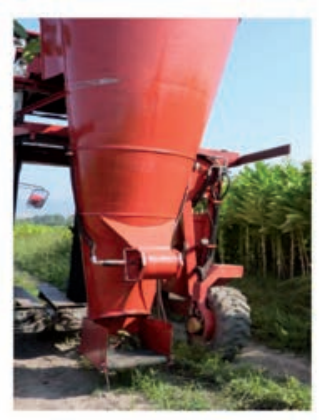

b)

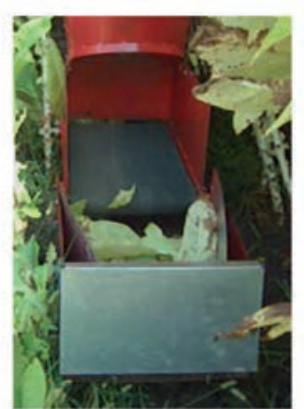

c)

Figure 1. a) The blower; b) pneumatic hopper; c) Conveyor belt and container. 
cultivars with three planting densities. The times recorded were, effective time $\left(\mathrm{T}_{\mathrm{E}}\right),(\mathrm{h} / \mathrm{ha})$; accessories time $\left(\mathrm{T}_{\mathrm{A}}\right)$ required for turning, driving in and out for refueling, transferring the load and calibration on field ( $h / h a$ ). The sum of $T_{E}$ and $T_{A}$ is equal to the operating time $\left(t_{0}\right)$ and is defined as the actual time for harvesting (Bolli et al. 1987). User working time $\left(t_{u}\right)$ that includes the preparation time on the field and operator rest was expressed as worker hour per hectare (w-h/ha). Row spacing and row length were also measured and used for calculating harvested area and associated to mass output in order to estimate average net yield.

\section{Quality of work}

Evaluation of the quality of work involved assessment of the integrity of the harvested leaves and their orientation. The harvested leaves were divided into three categories (Figure 2) i.e., i) intact leaves, that are those with whole leaf blade; ii) partially intact leaves, but totally appropriate, with less damages in the foil or damaged petioles; and iii) damaged leaves not suitable for further processing.

Data were collected on the first $50 \mathrm{~m}$ of each row. During the test, detached leaves were controlled by an operator and divided into damaged and undamaged. At the same time another operator examined every single plant and recorded the number of leaves removed per plant. To determine exactly the number of detached leaves from the plants fresh scars on the drums were counted. The orientation of leaves were also evaluated.
Field capacity and productivity were calculated from the times recorded in the field. Field capacity is defined as the rate at which a farm machine performs its primary function (Mark Hanna, 2001) and is expressed in ha/h. Productivity is the ratio of the unit yield to workers hours ( $w-h)$ required for the farm machine and is expressed as the $\mathrm{kg} / \mathrm{w}-\mathrm{h}$.

\section{Results and discussion}

Table 1 presents the results of time analysis of operations on the four cultivars.

User working time $\left(\mathrm{t}_{\mathrm{u}}\right)$, that is of greatest interest to farmers, ranged from 6.67 for the PM34 cultivar at a planting density $0.33 \mathrm{~m}$ to $7.80 \mathrm{~h} / \mathrm{ha}$ for the PM34 cultivar at a planting density $0.25 \mathrm{~m}$. Data reported in Table 1 shows that increase in plant density results in higher number of hours required to harvest an hectare. This is because of the reduced working speed observed when the plant density was increased.

Field capacity, productivity and gross-effective productivity associated with the operation of the prototype harvesting machine are shown in Table 2. The user field capacity showed no substantial differences with an average value of about $0.140 \mathrm{ha} / \mathrm{h}$, standard deviation $(\sigma)$ equal to 0.006 and Coefficient of variation (CV) equal to $4 \%$ for the effective and

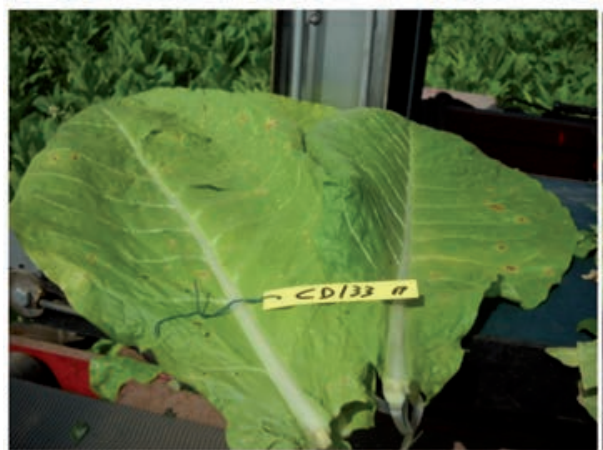

a)

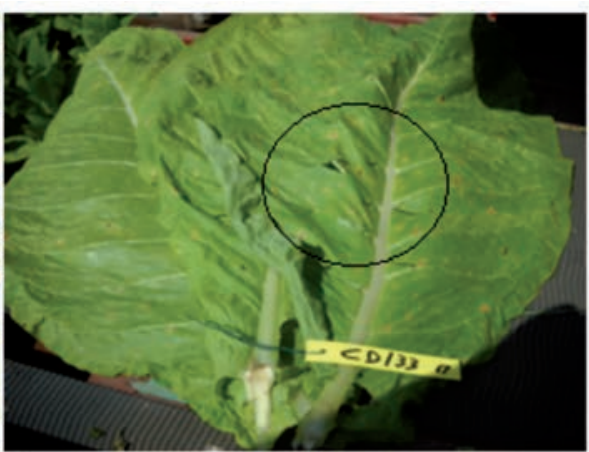

b)
Figure 2. Quality of work parameters a) Intact leaves; b)Partially intact leaves.

Table 1. Times results associated with the operation of Spapperi prototype burley harvesting machine.

\begin{tabular}{|c|c|c|c|c|}
\hline \multirow[t]{2}{*}{ Cultivar/ planting density (cm) } & \multicolumn{4}{|c|}{ Time elements } \\
\hline & $\mathrm{T}_{\mathrm{E}}(\mathrm{h} / \mathrm{ha})$ & $\mathrm{T}_{\mathrm{A}}(\mathrm{h} / \mathrm{ha})$ & $t_{0}(h / h a)$ & $t_{u}(w-h / h a)$ \\
\hline PM 34/25 & 6.7 & 0.84 & 7.54 & 7.8 \\
\hline PM 34/30 & 6.17 & 0.8 & 6.97 & 7.2 \\
\hline PM 34/33 & 5.65 & 0.77 & 6.42 & 6.67 \\
\hline $\mathrm{CD} / 25$ & 6.25 & 0.81 & 7.06 & 7.31 \\
\hline $\mathrm{CD} / 30$ & 6.13 & 0.82 & 6.94 & 7.16 \\
\hline $\mathrm{CD} / 33$ & 5.79 & 0.77 & 6.56 & 6.8 \\
\hline $\mathrm{DD} / 25$ & 6.27 & 0.83 & 7.1 & 7.36 \\
\hline $\mathrm{DD} / 30$ & 6.2 & 0.79 & 6.98 & 7.21 \\
\hline $\mathrm{DD} / 33$ & 5.98 & 0.76 & 6.74 & 6.99 \\
\hline $\mathrm{BD} / 25$ & 6.23 & 0.84 & 7.08 & 7.32 \\
\hline $\mathrm{BD} / 30$ & 6.21 & 0.8 & 7.01 & 7.25 \\
\hline $\mathrm{BD} / 33$ & 6.02 & 0.77 & 6.79 & 7.01 \\
\hline
\end{tabular}


Table 2. Field capacity, productivity and gross-effective productivity associated with the operation of Spapperi prototype burley harvesting machine.

\begin{tabular}{|c|c|c|c|c|c|c|c|c|}
\hline \multirow{2}{*}{$\begin{array}{l}\text { Cultivar/ } \\
\text { planting } \\
\text { density (cm) }\end{array}$} & \multicolumn{3}{|c|}{ Field capacity (ha/h) } & \multicolumn{3}{|c|}{ Productivity (kg/wh*) } & \multirow{2}{*}{$\begin{array}{c}\text { Gross-effective } \\
\text { productivity } \\
\text { (kg/ha) }\end{array}$} & \multirow{2}{*}{$\begin{array}{c}\text { Average value }(\%) \\
\text { of intact } \\
\text { leaves }\end{array}$} \\
\hline & Effective & Operative & User & Effective & Operative & User & & \\
\hline PM 34/25 & 0.149 & 0.133 & 0.128 & 206 & 183 & 177 & 5199 & 63.95 \\
\hline PM 34/30 & 0.162 & 0.144 & 0.139 & 231 & 205 & 198 & 3877 & 79.8 \\
\hline PM $34 / 33$ & 0.177 & 0.156 & 0.015 & 33 & 29 & 279 & 5147 & 74.3 \\
\hline $\mathrm{CD} / 25$ & 0.16 & 0.142 & 0.137 & 207 & 183 & 177 & 5199 & 60.35 \\
\hline $\mathrm{CD} / 30$ & 0.163 & 0.144 & 0.014 & 387 & 342 & 331 & 5510 & 58.55 \\
\hline $\mathrm{CD} / 33$ & 0.173 & 0.152 & 0.147 & 319 & 282 & 272 & 7119 & 62.2 \\
\hline $\mathrm{DD} / 25$ & 0.159 & 0.141 & 0.136 & 273 & 242 & 233 & 4545 & 55.4 \\
\hline $\mathrm{DD} / 30$ & 0.161 & 0.143 & 0.139 & 245 & 217 & 21 & 3669 & 66.95 \\
\hline $\mathrm{DD} / 33$ & 0.167 & 0.148 & 0.143 & 293 & 26 & 251 & 4974 & 62.75 \\
\hline $\mathrm{BD} / 25$ & 0.016 & 0.141 & 0.137 & 278 & 245 & 237 & 5741 & 62.15 \\
\hline $\mathrm{BD} / 30$ & 0.161 & 0.143 & 0.138 & 197 & 174 & 169 & 5256 & 69 \\
\hline $\mathrm{BD} / 33$ & 0.166 & 0.147 & 0.143 & 273 & 242 & 235 & 4929 & 61.2 \\
\hline
\end{tabular}

operative capacity. However, the field capacity is very far from that reported for bright-leaf tobacco harvesting machine that is about $0.25 \mathrm{ha} / \mathrm{h}$.

\section{Quality of work}

Results of the quality of work are reported in the Table 2 . The number of tobacco plants uprooted or broken during the harvesting test was about two to three plants per row, caused by a misalignment of the plants, or from an oblique growth. The mean value of intact leaves for the four cultivars was $64.7 \%$, and the four cultivars showed very little variation in quality with a CV value of $10 \%$. This corresponds to a loss of 0.17 tha of fresh tobacco, which is less significant for the case of the PM34 cultivar.

The last work quality parameters evaluated was the leaves orientation efficiency. These tests were carried out both with stationary machine and with moving machine. In the first case, the leaves were fed in manually. The best results were obtained in tests with stationary machine, with about $75 \%$ of the leaves well oriented. Tests carried out in the field showed a reduction in the percentage well oriented of leaves to $70 \%$. This difference depends on the number of leaves that reach the hopper. It was observed that lower value of well oriented always corresponded to overloading of the hopper.

\section{Future work}

The Tab.IT project, is a three-year project beginning from 2010 to 2013 , and will continue for another burley tobacco season. The first year was used to study and design the prototype. During the first burley tobacco season involved organizing the first version of the prototype, in which the sewing phase was on the top of the harvesting machine. This prototype required three workers to operate it and was considered unsuitable for both the excessive human labor and for safety reasons. The second prototype, presented in this paper, did not show encouraging results. This because an harvesting machine must guarantee a certain amount of work and at the same time must guarantee the commercial quality of the harvested product. Future work will aim at improving these attributes.

\section{Conclusions}

In this study, we developed and evaluated a prototype barley tobacco harvester. The best operating time performance obtained was 6.67 $\mathrm{h} / \mathrm{ha}$, far less from than performance of Bright-leaf tobacco harvester, which is reported to be $4 \mathrm{~h} / \mathrm{ha}$. Also, the harvested product quality highlighted unacceptable losses of approximately 30\%. However, results showed very good levels of leaves orientation made directly on the machine of about 73\%. Even in this case an improvement of the prototype will still be advantageous.

The poor performance in terms of field capacity of the machine, which advance with an average speed of $0.5 \mathrm{~m} / \mathrm{s}$, is probably caused by excessive plant density, which results in very tall tobacco plants. The very tall plants results in forward bending and consequently damage to leaves. Also this aspect has to be considered, in fact even if the burley tobacco has generally a lower height of tobacco Bright, it is not possible to perform topping operation. This because topping operation would entail an excessive accumulation of nicotine in the leaves, aspect considered negative.

\section{References}

Bolli P. Scotton M. Lineamenti di tecnica della meccanizzazione agricola. - Bologna :edagricole, 1987. - p. 47-56,107-120.

Casada JH, EM. Smith, CF. Abrams. 1972. A mechanical harvester for stalk-cut tobacco. Tobacco Science 16:147-149.

C.R.A.A. 2006. Miglioramento dell'efficienza della fase primaria nella filiera del Burley available on line: http://www.agricoltura.regione. campania.it/erbacee/pdf/report-burley.pdf

Di Carlo M. 2012. L'incerto futuro del tabacco italiano - L'Informatore Agrario. 15: 16.

Duncan GA, SA. Shearer, B. Tapp, CL. King. 1999. A new floating spear 
mechanism for impaling burley tobacco plants onto a wooden stick. Applied Engineering in Agriculture 15(5):383-387.

Duncan GA, LR. Walton, JH. Casada, LD. Swetnam, B. Tapp. 1996. Development and evaluation of a cable-hoist system for housing burley tobacco. Applied Engineering in Agriculture 12(4):411-416.

Hanna M. 2001. Estimating Field Capacity of Farm Machines Machinery Management - available on line at http://www.extension.iastate.edu/publications/pm696.pdf

ISTAT Istituto Nazionale di Statistica [Italian National Institute of Statistic], 2010. 6th General Census of Agriculture, Italy.
NOMISMA, 2011. La filiera del tabacco in Italia - Impatto socioeconomico ed aspetti di politica fiscale XV Rapporto (available on line at http://www.nomisma.it/fileadmin/User/XV_rapp_tabacco_2011.pd)

Wells L.G., Smith T.D., Day V G.B., Harpring M. 2011. On-farm performance of a mechanical burley tobacco harvesting system. Tobacco Science. 48:1-6

Yoder EE, WH. Henson, Jr. 1974. Handling burley tobacco on portable curing frames. Agricultural Information Bulletin No. 366. GPO, Washington, DC. 